\title{
Living status and support system of children orphaned by AIDS in central China-Description and policy recommendations
}

\author{
Xiaohui $\mathrm{Gao}^{1^{\star}}$, Yu Wu ${ }^{2 *}$, Yali Luo ${ }^{3}$, Naixing Zhang ${ }^{4}$, Weimin Fang ${ }^{5}$, Yukai $\mathrm{Du}^{5 \#}$ \\ ${ }^{1}$ Shenzhen Maternal and Child Health Hospital, Shenzhen, China \\ ${ }^{2}$ Shenzhen Center for Disease Control and Prevention, Shenzhen, China \\ ${ }^{3}$ Department of Epidemiology, School of Public Health and Tropical Medicine, Southern Medical University, Guangzhou, China \\ ${ }^{4}$ Department of Social Medicine and Health Management, School of Public Health, Tongji Medical College, Huazhong University of \\ Science \& Technology, Wuhan, China \\ ${ }^{5}$ Department of Child \& Maternal Health Care, School of Public Health, Tongji Medical College, Huazhong University of Science \& \\ Technology, Wuhan, China; ${ }^{\#}$ Corresponding Author: duyukai100@163.com
}

Received 20 September 2012; revised 24 October 2012; accepted 31 October 2012

\begin{abstract}
This study aimed to research the living status and support system of children orphaned by AIDS in rural Henan Province. The approach of face-to-face questionnaires research was used to assess 501 children's current situation while in-depth interview was conducted for the support system research. The age range of the children orphaned by AIDS was 2 - 15 years old and the mean age was 11.10 years. Most children among 2 - 6 years had communication skills with temper control and psychological problems. Children of $7-15$ years old had the ability to take care of themselves and family members but could not do self-regulation. The support system for children orphaned by AIDS included social support, policies support, education support, and health care support but improvement are needed in the future. Support system can be improved through much more feasible and concrete policies and strategies to guarantee these children's basic needs and comprehensive development.
\end{abstract}

Keywords: HIVIAIDS; Orphans; Support System; China

\section{INTRODUCTION}

HIV/AIDS is a supremely complex issue that demands an unparalleled response from all sectors of society and is recognized worldwide as a threat to children [1]. At

*These two authors contribute equally to this work. the end of 2010, an estimation of 34 million people [31.6 million - 35.2 million] was living with HIV worldwide [2]. Globally, the number of children younger than 15 years living with HIV increased from 1.6 million [1.4 million - 2.1 million] in 2001 to 2.0 million [1.9 million 2.3 million] in 2007 [1]. There were more children affected by AIDS than infected. Over 15 million children have been orphaned or made vulnerable by HIV/AIDS [3].

Children orphaned by AIDS refer to children and adolescents under 18 years old who have lost one or both parents due to AIDS [4]. There is a large number in Asia, especially in China. UNAIDS and UNICEF estimated that in some countries with large population, such as China, the number of children orphaned by AIDS would grow dramatically if the HIV/AIDS epidemic expands to a level as high as Thailand and Cambodia [3]. The China Ministry of Health $(\mathrm{MOH})$ has estimated that there are at least 100,000 children orphaned by AIDS in China [5].

Children orphaned due to AIDS are affected early in their parent's illness, and its impact continues during the course of the illness and throughout the child's development after the parent's death [3]. They may receive inadequate nutrition and care, be exposed to infections, and be denied health services [6]. They may also be pulled out of school to work when family financial burdens increased. If both parents die, orphaned children may have to stay at home to care for their younger siblings [7].

The Chinese government has made a series of responses to provide support for these children, including "Four Free and One Care" policy announced in December 2003 [8] and building AIDS orphanages in highly epidemic areas in late 2004 [9]. Most of the children orphaned by AIDS live in Henan Province, the first province building AIDS orphanage in China. Henan Province 
is an agricultural province in central China with a large number of 98.69 million population with 64.80 million were farmers [9]. In the late 1980s, some commercial blood stations and centers collected cheap blood in remote rural areas of this Province. Because of extreme poverty, many farmers sold blood to those centers that used unhygienic blood collection procedures, resulting in the rapid spread of HIV [10]. Many of the infected people died subsequently, leaving their children behind [11].

Previous studies on children orphaned by AIDS in Henan Province have shown that stigma and discrimination remains a serious problem for children [12] who had worse performance in school than non-orphans [13]. Social support, psychosocial distress, care arrangement of these children need to be paid more attention [14,15], therefore. However, there have been few studies conducted to explore the current situation under the support system and the strategies of each support institution among children orphaned by AIDS in Henan Province. To address this gap and provide a basis for intervention models, a cross-sectional study was conducted in Shangcai County, Henan Province, China.

\section{METHODS}

\subsection{Study Site}

The study was conducted from July 2008 to March 2009 in Shangcai County, with a population of 1.39 million situated in Henan Province in central China. The County has an estimation of 7412 HIV-positive patients by the end of April 2008 through unhygienic blood collection [12]. The study sites covered 5 HIV high-prevalence towns including Wulong, Shaodian, Lugang, Yangtun, and Qihai Town. The majority of inhabitants in these villages live on agriculture and subsistence farming and most of the children orphaned by AIDS are living there [16].

\subsection{Design}

The study design was a cross-sectional research. Both qualitative and quantitative methods were used in this study. The qualitative methods included in-depth interviews while the quantitative component consisted of a face-to-face questionnaire survey.

\subsection{Participants}

The participants of quantitative study included 195 double orphans (i.e., children who lost both parents to AIDS) and 306 single orphans (i.e., children who lost one parent to AIDS). Children 1 - 18 years of age were eligible to participate in the study. Age eligibility was verified through the local village leaders, orphanage masters, or caregivers.
The participants of qualitative study refer to people who take change of the children's daily life arrangement and schooling, including one local civil affairs manager, one local health bureau manager, and one local education bureau leader.

\subsection{Sampling}

The children sample was recruited from governmentfunded orphanages, extended families and single-parent families using the cluster sampling. Local Health Bureau has the list and address of all children orphaned by AIDS in Shangcai County, making it easier to find them under the help of local administers.

\subsection{Survey Procedure}

All of the investigators and cooperators were trained 3 - 5 times at the beginning of the research. Once the eligibility of a child was confirmed, the interviewers informed the study design as well as the potential benefits, and then, invited him or her to answer the questionnaire. Written pattern was used for 12 - 18 years old children because they could totally understand the questions while oral style for those under 12 years old children. Caregivers could be asked if the children were too young to understand. It took about 15 - 20 minutes to finish the whole questionnaire. Each child received a gift like towel and toothbrush at the end of the survey.

In-depth interviews were conducted with an outline taking 45 - 50 minutes that included what kind of support had been carried out for the children orphaned by AIDS, current effectiveness and difficulties. All of the content was recorded by writing and recording.

\subsection{Measures}

Participants were divided into two groups: 1 - 6-yearold (pre-school aged children) and 7 - 18-year-old (school-aged children and adolescents). Each group was asked to provide a number of individual and family characteristics such as gender, nationality, and age, single/double orphans etc. Pre-school aged children were asked to answer several questions about their life skills. School-aged children should do the same but their questions were more complicated. In addition, the schoolaged children should provide the information about their schooling. All children were asked to descript their health and life condition as well as social support according to some designed items. They were allowed to compare some aspects of their current life with those before the death of their parents.

\subsection{Data Analysis}

The two sets of data (qualitative and quantitative) 
were analyzed separately. Microsoft Word 2003 was used for the qualitative data from the in-depth interviews, while Statistical Package for Social Sciences software (SPSS for Windows 15.0, SPSS Inc., Chicago, IL) for the quantitative data. All data analysis was done by the first author of this article. Frequency distribution and mean, rate was done as a description of the data. Chisquare test was used to examine the group differences among children in four care arrangements in individual characteristics, with significance set at $\mathrm{p}<0.05$.

\subsection{Informed Consent and Ethical Considerations}

The research protocol including instruments was reviewed and approved by the Ethical Committee of the Medical Association of a Medical College of Tongji Medical College of Huazhong University of Science and Technology.

\section{RESULTS}

\subsection{Characteristics of the Sample}

As shown in Table 1, the study subjects in this study were consisted of 270 (53.9\%) boys and 231 (46.1\%) girls. The children's age ranged from two to fifteen years old with a mean age of 11.10 years. There were 226 (45.1\%) children in the kinship care sample and 187 (37.3\%) were living with their surviving parent. All of them were Han nationality. No gender difference was observed in all items of care arrangement. Table 2 showed that nearly forty percent children (195, 38.92\%) had lost both of their parents. Single-orphaned children were classified into 4 varieties, among which 154 children's survival parent were HIV infectors or AIDS patients.

\subsection{Life Skills Situation}

Our study found that among 2 - 6-year-old children, about $97.7 \%$ (42/43) could play games with others and $76.7 \%$ (33/43) had no problem in maintaining friendship. Nevertheless, nearly one third of them (12/43) could not control their temper, $44.2 \%$ had dietary problems and $39.5 \%$ had psychological problems.

More than $90.0 \%$ of the 7 - 15-year-old children were able to take care of themselves and do some housework when the adults were out of home or sick. As to the

Table 1. Demographic Characteristic of Study Subjects.

\begin{tabular}{|c|c|c|c|c|c|}
\hline Variable N (\%) & Overall & Kinship Care & Single Parent & Extended Family & Orphanages \\
\hline N (\%) & $501(100)$ & $226(45.1)$ & 187 (37.3) & $52(10.4)$ & $36(7.2)$ \\
\hline \multicolumn{6}{|l|}{ Gender $^{\mathrm{a}}$} \\
\hline Boy & 270 (53.9) & $120(53.1)$ & 112 (59.9) & $23(44.2)$ & 15 (41.7) \\
\hline Girl & $231(46.1)$ & 106 (46.9) & $75(40.1)$ & 29 (55.8) & $21(58.3)$ \\
\hline \multicolumn{6}{|l|}{ Nationality } \\
\hline Han & $501(100)$ & $226(45.1)$ & 187 (37.3) & $52(10.4)$ & $36(7.2)$ \\
\hline Mean Age (SD) & $11.10(2.96)$ & $10.62(2.73)$ & $11.04(3.15)$ & $11.44(2.82)$ & 13.89 (1.79) \\
\hline \multicolumn{6}{|l|}{ Age (years) } \\
\hline $2-6$ & $43(8.6)$ & $20(8.8)$ & $19(10.2)$ & $4(7.7)$ & $0(0.0)$ \\
\hline 7 & $15(3.0)$ & $8(3.5)$ & $7(3.7)$ & $0(0.0)$ & $0(0.0)$ \\
\hline 8 & $43(8.6)$ & 20 (8.9) & $18(9.6)$ & $4(7.7)$ & $1(2.8)$ \\
\hline 9 & $41(8.2)$ & 33 (14.6) & $7(3.7)$ & $1(1.9)$ & $0(0.0)$ \\
\hline 10 & 55 (11.0) & 25 (11.1) & $21(11.2)$ & $9(17.3)$ & $0(0.0)$ \\
\hline 11 & $56(11.2)$ & $28(12.4)$ & $19(10.2)$ & $4(7.7)$ & 5 (13.9) \\
\hline 12 & 64 (12.8) & $26(11.5)$ & $26(14.0)$ & $10(9.2)$ & $2(5.6)$ \\
\hline 13 & $56(11.2)$ & 27 (12.0) & 22 (11.8) & $6(11.5)$ & $1(2.8)$ \\
\hline 14 & $56(11.2)$ & $25(11.1)$ & $19(10.2)$ & 7 (13.5) & 5 (13.9) \\
\hline 15 & $72(14.4)$ & $14(6.2)$ & 29 (15.5) & $7(13.5)$ & 22 (61.1) \\
\hline
\end{tabular}

${ }^{a} \mathrm{p}>0.05$. 
Table 2. Parents' living situation of children orphaned by AIDS ( $\mathrm{N}=501)$.

\begin{tabular}{cccc}
\hline Father & Mother & N & $\%$ \\
\hline Dead & Healthy & 84 & 16.77 \\
Dead & HIV infectors/AIDS patients & 87 & 17.37 \\
Dead & Dead & 195 & 38.92 \\
HIV infectors/AIDS patients & Dead & 67 & 13.37 \\
Healthy & Dead & 68 & 13.57 \\
\hline
\end{tabular}

self-regulation skills, worthy of note only $67.5 \%$ (309/458) children can make themselves happy through watching TV or playing games when upset.

\subsection{Daily Life Situation}

A number of 494 children were looked after well by their single parent or caregivers. Over half of the children (60.7\%) having a bath every day and $46.9 \%$ buying new clothes at least once a year. About $80.4 \%$ children considered their neighbors did not changing attitude after their parents deceased. Almost all children reported no basic food and clothing problems (95.8\%). But as to nutrition level, most children's meat, fruit, and eggs intake was too low to meet their physical growth.

\subsection{Medical Care Situation}

In this study, 83.8\% (280) children who had upper respiratory tract infection in the past two weeks followed by intestinal diseases $(5.39 \%, 18)$. More than half of the children's medical costs were paid by their single parent or caregivers. The proportion of free drugs was only $34.1 \%$. Although the medical expenses after the illness were not high, always less than 50 Yuan, they accounted for a large expenditure for an AIDS affected family, which always at the edge of the poverty line. As high as $44.8 \%$ children did not have physical exam once a year and the remaining $34.88 \%$ had it only once a year.

\subsection{Schooling Situation}

Teachers in school were aware of the "orphans" word-the name given to the children which was too painful for them to build confidence, so they never use it. Now, about $98.1 \%$ children were enrolled in school expect 9 school-aged children mainly because they had not prepared to study yet. However, more than half (50.7\%) of the children had low academic marks.

\subsection{The Support System}

\subsubsection{Social Support}

There were 18 (5.0\%) children had been subsidized by social individuals in a long term and 222 (44.3\%) children had received money from individuals or Non-Government Organizations ranged from 50 - 3000 Yuan periodically. Clothes and living goods were also donated sometimes.

\subsubsection{Civil Affairs Department Policies Support}

Financial Aid The In-depth interview results showed that local civil affairs department provided a monthly living allowance with the amount of 160 Yuan for each child orphaned by AIDS in 2006, and then 200 Yuan per child since 2008 with the form of a real-name bank card. Besides, if the children live in a family affected by AIDS, they could receive 210 - 280 Yuan per month.

It is enough for one child's daily life in this district if their caregivers do not use the money in other sides. Actually, most caregivers will use the money to resolve other things which has no relationship with these orphans. It is hard to intervene because it is the family affair.Manager of civil affairs.

Care Arrangement Except the way that children stayed with their surviving biological parent; there were four other ways to arrange these children: adoption, institutional care, kinship care and extended family care. The civil affairs manager indicated that adoption was the best way to resettle them. But only a few children were adopted because some children's relatives did not regard it as a good way and children were reluctant to enter a strange family. That's why our study could not find even one adopted orphan. There were three orphanages in Shangcai County in total: Sun Orphanage; Xinhe Orphanage; Red Tie Orphanage. They were in charge of daily life, schooling, and medical care, with a kind of semi-militarization management. In Xinhe Orphanage, there were a number of group homes, managed by pairs of local residents serving as house parents for 4 - 6 children in a family style. This kind of institutional support was responsible only for children until middle school graduation. If these orphans were admitted into high school or university, the orphanages just give them a monthly living allowance of 100 Yuan and 300 Yuan respectively.

Living in the orphanages can help children to forget 
the traumatic event because so many friends who can have interesting talks with them. They don't need to face their deceased parents' pictures handing on the wall in their own house which lead them to feel bad every day.-Manager of the orphanage.

\subsubsection{Education Department Policies Support}

Local Education Bureau was in charge of children's school admission and preferential policies. Local school adopted "Two Frees and One Subsidy" policy for children orphaned by AIDS, that is, providing free books and cut down other fees and providing life allowance for them until they finished high school study [3]. If children did not attend high school when graduating from middle school, they can take part in vocational training including car driving, automobile repair, electricians, machine tools, decoration and computer. Besides, if these children take part in the college entrance examination, there was some priority for them.

\subsubsection{Health Care Department Policies Support}

Families affected by AIDS can attend the New Rural Cooperative Medical System for free with a premium of 300 Yuan a month. The principles of the cooperative medical were that totally free for less serious sick and partly free for serious illness, organizing children's physical examination at least once a year. If new infected children were found in the examination, the children will be incorporated into the children's AIDS fund system, with which they had the opportunity to receive faceto-face treatment by the international or national experts.

\section{DISCUSSION}

This study indicated that children orphaned by AIDS had life skills in certain extent except in some aspects such as emotional and psychological regulation. Care from guardians can meet children's basic needs except for meet their nutrition needs. Most children were vulnerable to fall ill. Support system including social support, civil affairs department support, education department support and health care department support had been established to provide the corresponding polices and strategies, however, improvement and strength were also needed in some aspects.

First, publicity and education of AIDS knowledge should be reinforced to reduce social stigma and discrimination [17]. Government sectors should encourage all society involvement style to provide money or living necessity for children orphaned by AIDS.

Moreover, care arrangement needs optimization. In this research, there were 187 (37.3\%) children lived with their surviving parent. Yet, the surviving parent was always in bad health status due to HIV/AIDS which in- creases children's risk of infectious disease. Therefore, community-based home care would be situated to identify children in these difficult circumstances [6]. Government-founded orphanages have advantages including stable living and learning environment, improved medical care and psychological support [18]. However, there are some disadvantages of orphanages such as need for psychological guidance and financial burdens. Thus, orphanages need to change their administrative style and seek more financial support. Meanwhile, workers and caregivers in orphanages should receive adequate psychological training to provide basic emotional support to these children $[9,19]$.

Third, regular school attendance is very important for these children to get self-confidence [20]. Providing educational opportunities and non-discrimination educational environment would be vital to help them to forget resentment and anger, receiving more social support and having a light future. Meanwhile, appropriate intervenetions should be undertaken to promote school performance of children orphaned by AIDS because of their low academic record at present [21].

\section{CONCLUSION}

Social support, care arrangement, financial support, education policies support, as well as health care policies support are needed to improve the support system of children orphaned by AIDS. Further researches, particularly that address multi-department cooperation, are warranted to develop a complete network that guarantees these children's basic needs and comprehensive developments.

\section{LIMITATIONS}

Certain limitations of this study were needed to be acknowledged. First of all, the sample selected in this study covered just one county in Henan Provence, thus could not be representative of other areas in China. Second, current situation and support system was investigated in the Han nationality only in this cross-sectional study. Last but not the least, cluster sampling was applied in this study, by which selection bias might be introduced.

\section{ACKNOWLEDGEMENTS}

The research was supported by AIDS Prevention Committee of State Department and National Natural Science Foundation of China (NSFC, NO. 30700677). We thank for the Child and Woman Healthcare Hospital in Shangcai County, Henan Provence.

\section{REFERENCES}

[1] UNAIDS (2008) Report on the global AIDS epidemic. 
[2] UNAIDS (2011) UNAIDS world AIDS day report.

[3] UNAIDS/UNICEF (2004) Children on the Brink.

[4] UNICEF (2009) Responding to children, young people and AIDS.

[5] Zhao, G., Li, X., Fang, X., Zhao, J., Yang, H. and Stanton, B. (2007) Care arrangements, grief and psychological problems among children orphaned by AIDS in China. AIDS Care, 19, 1075-1082. doi:10.1080/09540120701335220

[6] Kidman, R., Hanley, J.A., Subramanian, S.V., Foster, G. and Heymann J. (2010) AIDS in the family and community: The impact on child health in Malawi. Social Science \& Medicine, 71, 966-974. doi:10.1016/j.socscimed.2010.05.027

[7] Traube, D., Dukay, V., Kaaya, S., Reyes, H. and Mellins, C. (2010) Cross-cultural adaptation of the child depresssion inventory for use in Tanzania with children affected by HIV. Vulnerable Children and Youth Studies, 5, 174187. doi:10.1080/17450121003668343

[8] Wu, Z., Sun, X., Sullivan, S.G. and Detels, R. (2006) Public health. HIV testing in China. Science, 312, 14751476. doi:10.1126/science. 1120682

[9] Zhao, Q., Li, X., Kaljee, L.M., Fang, X., Stanton, B. and Zhang, L. (2009) AIDS orphanages in China: Reality and challenges. AIDS Patient Care STDS, 23, 297-303. doi:10.1089/apc.2008.0190

[10] Cohen, J. (2004) HIV/AIDS in China: An unsafe practice turned blood donors into victims. Science, 304, 14381439. doi:10.1126/science.304.5676.1438

[11] Zhao, Q., Li, X., Fang, X., Zhao, G., Zhao, J. and Lin, X. (2010) Difference in psychosocial well-being between paternal and maternal AIDS orphans in rural China. Journal of Association of Nurses in AIDS Care, 21, 335-344. doi:10.1016/j.jana.2009.12.001

[12] Zhao, J., Li, X., Fang, X., Hong, Y., Zhao, G. and Lin, X. (2010) Stigma against children affected by AIDS (SACAA): Psychometric evaluation of a brief measurement scale. AIDS and Behavior, 14, 1302-1312. doi:10.1007/s10461-009-9629-8

[13] Tu, X., Lv, Y., Li, X., Fang, X., Zhao, G. and Lin, X. (2009) School performance and school behavior of chil- dren affected by AIDS in China. Vulnerable Child Youth Studies, 4, 199-209. doi:10.1080/17450120902814420

[14] Hong, Y., Li, X., Fang, X., Zhao, G., Lin, X. and Zhang, J. (2010) Perceived social support and psychosocial distress among children affected by AIDS in china. Community Mental Health Journal, 46, 33-43. doi:10.1007/s10597-009-9201-z

[15] Zhao, Q., Li, X., Fang, X., Stanton, B., Zhao, G. and Zhao, J. (2009) Life improvement, life satisfaction, and care arrangement among AIDS orphans in rural Henan, China. Journal of Association Nurses in AIDS Care, 20, 122-132. doi:10.1016/j.jana.2008.09.009

[16] Zhao, Q., Li, X., Lin, X., Fang, X., Zhao, G. and Zhao, J. (2009) Knowing kids dying of HIV: A traumatic event for AIDS orphans. Journal of Association Nurses in AIDS Care, 20, 275-282. doi:10.1016/j.jana.2009.02.005

[17] Messer, L.C., Pence, B.W., Whetten, K., Whetten, R., Thielman, N. and O’Donnell, K. (2010) Prevalence and predictors of HIV-related stigma among institutional- and community-based caregivers of orphans and vulnerable children living in five less-wealthy countries. BMC Public Health, 10, 504. doi:10.1186/1471-2458-10-504

[18] Jelsma, J., Davids, N. and Ferguson, G. (2011) The motor development of orphaned children with and without HIV: Pilot exploration of foster care and residential placement. BMC Pediatrics, 11, 11. doi:10.1186/1471-2431-11-11

[19] Han, M., Chen, Q., Hao, Y., Hu, Y., Wang, D. and Gao, Y. (2010) Design and implementation of a China comprehensive AIDS response programme (China CARES). International Journal of Epidemiology, 39, 47-55. doi:10.1093/ije/dyq212

[20] Okawa, S., Yasuoka, J., Ishikawa, N., Poudel, K.C., Ragi, A. and Jimba, M. (2011) Perceived social support and the psychological well-being of AIDS orphans in urban Kenya. AIDS Care, 1-9.

[21] Xu, T., Wu, Z., Duan, S., Han, W. and Rou, K. (2010) The situation of children affected by HIV/AIDS in Southwest China: Schooling, physical health, and interpersonal relationships. Journal of Acquired Immune Deficiency Syndromes, 53, 104-110. doi:10.1097/QAI.0b013e3181c7df8b 